Open Access

\title{
Complex spaces: global innovation networks \& territorial innovation systems in information \& communication technologies
}

Philip Cooke

Correspondence:

CookePN@cardiff.ac.uk

Center for Innovation and Regional Development, West Norway University of Applied Sciences, Bergen, Norway

\begin{abstract}
This paper brings together two related bodies of theory that assist understanding of processes of socio-technical system change on the global scale. These are, first, the Global Value Chain perspective (GVC) that has now mutated into Global Production Networks (GPN) and, more recently, Global Innovation Networks (GIN). Examples of why this should be are exemplified (e.g. Scandinavia's mobile telephony 'creative destruction'). The second perspective is that of Territorial Innovation Systems. This addresses the innovative core of 'creative destruction' events which, in turn, explains economic growth and development. In recent times this has been significantly undergirded by means of concepts like 'relatedness', 'proximity' and 'path dependence'. These perspectives are combined to produce a framework for analysing the contribution of an increasingly commoditised ICT assembly industry to high-value, customised 'chipset' and 'apps' design around smartphones, netbooks and flat panel display (FPD) technologies that express the GIN/TIS complex in global 'value curve' integration. Here 'creative destruction' recombinations arise because, from an evolutionary perspective, the regions in which they emerge display technological 'relatedness' and regional 'regimes' that foster co-innovation, in this case ICT-based co-innovation.
\end{abstract}

\section{Introduction}

This paper will home in on a spatial understanding of today's rapidly changing ICT technology platforms in convergent ICT in the smartphones, tablets, netbooks and flat screen products businesses in key innovative growth and transitioning regions of northern Europe, California and Asia Pacific, notably China, Taiwan and South Korea. The paper is set at something of a trisection among economic geography, international business and development studies (on aspects of this, see Beugelsdijk, McCann \& Mudambi, 2010). In regard to the first, the paper examines the process of transition in global system architecture. In brief, this means exploring change processes in complex adaptive systems, seen as 'systems that have large numbers of components, often called agents, that interact and adapt or learn' (Holland, 2006; see also Kauffman, 2008; Cooke, 2012). In this instance, the focus is upon the inheritance of the global ICT industry from a hierarchical, linear, multinational corporation (MNC) orchestrated 'global value chain'(GVC) evolved into a still-linear, hierarchical 'global production network' (GPN) different for two reasons. First, because states, through their national

(c) The Author(s). 2017 Open Access This article is distributed under the terms of the Creative Commons Attribution 4.0 International License (http://creativecommons.org/licenses/by/4.0/), which permits unrestricted use, distribution, and reproduction in any medium, provided you give appropriate credit to the original author(s) and the source, provide a link to the Creative Commons license, and indicate if changes were made. 
innovation systems (NIS), both guaranteed foreign (often US) direct investment (FDI) agreements and potentialities (e.g. regarding research, skills and hardware investments in support of FDI). Second, NISs also arrange the elaboration of subsidiary GPNs such as those elaborated by Singapore in hard disk drives among Malaysia, Thailand, the Philippines and India or Taiwan in components regarding its silicon foundry, FDI acquisitions and cross-straits relations with China's 'world factory'.

From the second viewpoint, that of international business, of key interest in the paper is the erosion and change in roles of firms in the eclipse of GVC and GPN relationships at the global scale. A key part of this erosion and change is technological, organizational and cultural evolution in market demand and innovative response. Sufficient has changed, even in the past four or five years or so to render some of the conclusions of insightful accounts of experts such as Mudambi (2008) open to question and revision. In particular, this paper concurs that a big shift in business relations, market demand and the culture of 'new combinations' of commercial modularization (e.g. wireless radio, camera, music, video, film, computing, Internet, etc. and integrative systems design) testifies to the emergence of an ICT 'global innovation network' (GIN). This has the characteristics of a complex adaptive system with non-linear and distributed innovation characteristics without the single hierarchical force of the Western MNC driving it. Rather, innovation occurs in distinctive territorial innovation systems (TIS) clustered at key nodes in the GIN. The term TIS is preferred to NIS, first, because neither South Korea nor Taiwan are officially nations, both being disputed parts of a greater geopolitical whole. But second, key parts of the rest of the current ICT GIN are not national either but elements of regional innovation systems (RIS). This is true of epicentres at Silicon Valley in the US, where Apple and Google prevail; Eastern England and particularly Cambridge where ARM and CSR similarly prevail with $99 \%$ of the market for smartphone chipsets; the regions of Sweden, Denmark and Finland that are today being eclipsed by smartphone innovation, and the Pearl River and Yangtse Delta regional systems of China that are doing much of the eclipsing. In this part of the paper, the eclipsing and dawning of firm influence is analytically paramount.

The third body of literature that is tangentially addressed in this paper concerns development studies. It is tangential primarily because few of the political players are classic 'developing countries' though China has some such characteristics. Most are, accordingly, developed countries, newly industrialised countries or - China again 'emerging markets'. However, what is of more central relevance is changing conceptual frameworks. Fundamentally, as will be seen in more detail later, development studies is wedded to a linear and hierarchical view of the global value system, which is captured in the 'chain' terminology. As is also shown below, this has been subject to an autocritique which elaborates five more or less complex variants on the basic 'chain' metaphor. This is partly because the GVC discourse seeks to be able to generalise about different globalized industries. But because it retains a notion of $\mathrm{MNC}$ domination at every link of the chain, it arguably loses leverage in advanced technology industries like ICT, and conceivably also automotives, where globally regionalized innovation systems such as Sao Paulo in Brazil produce more advanced bio-engines for cars and trucks than the West or China does. In the same way, the paper's focus on ICT points to South Korea and Taiwan definitely, and RISs in China, probably, producing superior innovations in implementing chip-integration than US leaders like Texas Instruments and 
Broadcom. This is an extremely valuable insight for development studies in showing the varied ways development to the point of surpassing western innovation hegemony actually occurs.

Accordingly, the key intention of the paper is to seek to divulge key elements and processes by which in the ICT global network, TIS set-ups assisted indigenous firms and, especially, firm ecosystems to innovate in significant ways that enable agents to interact or adapt and learn. To do this the paper aims to show, analytically, how the torch of innovation was passed to a new generation of innovative Asian businesses at the expense of the Western (radical) innovators who pioneered mobile telephony (Alcatel, Siemens, Motorola, Ericsson, Nokia - and in GSM infrastructure, Denmark's NorCOM cluster). The open question, which the paper inclines to answer in the negative at present, is to what extent are the emergent torch-carriers in Asia likely to emulate Western radical innovation in ICT or any other industry? The inclination to the negative arises for three reasons that may be advertised beforehand. First, Western radical innovation is embedded in an extremely deep cultural earth that lends itself to global understanding and heightening demand. Western popular digital electronic culture has a unique capability of self-reflexivity and reincarnation as a next-generation globally commercial good. Second, the power of this influence is signified even where a rising pioneer like China's animation segment of its emergent computer games culture reveals eight of the top ten games companies registering on Apple's expensive App Store rather than cheaper domestic equivalents (Cooke, 2013). Hence maximization of returns and/ or reputational capital remains at the behest of Western dominated rather than indigenous markets. Finally, radical innovation in the West has shifted into significant novelty with ICT support in advanced, knowledge-intensive services. One only has to think of innovations like the 'servicization' of ICT led by IBM and Honeywell, later to be dallied with by the likes of Hewlett-Packard. Indeed, existentially, the question of whether Apple, let alone Google, are in any significant ways manufacturing firms falls in this self-same category. Elsewhere, as in structured finance with collateralized debt obligations (CDOs) or credit default swaps (CDSs) Asian institutions were often the end-ofthe-line purchasers of the toxic bonds or lifeboats for their failed originators rather than in any way financial innovators (Lewis, 2010).

The paper is structured as the following narrative. The section which follows introduces the broad outlines of the GVC> > GPN > > GIN shift registering winners and losers. The section which follows that is concerned with theory, outlining the elements of complexity theory that help us get a better grasp on the non-linear, considerably 'self-organizing' evolution of ICT's complex GIN than previous, linear approaches

The third and fourth sections explore the economic geography of the transition from GVC through GPN to GIN by reference to anatomies of the key TIS nodes in the GIN for ICT. For ease of reading, the upper reaches of the 'smiling curve' of value in the GIN are dealt with first, the rising elements, second. There follows a final section of discussion and conclusions.

\section{Outline of complex system adaptation in global ICT}

The paper goes beyond the inherited view of globalization in ICT while recognising that a conflict perspective (Buckley and Ghauri, 2004) may be too strong to capture subtle design shifts that entail positive feedbacks. For modest stability, these require 
tempering by negative feedback effects (reorganization, control, regulation) but subtle shifts may entail larger global impacts. The paper thus prefers a discourse of displacement, emergence and evolution. The case in point is the amplifying shift from a desktop PC-based, MNC-dominated GPN that is currently being displaced by an emergent GIN based on smartphones and tablets (Chen \& Wen, 2011; Chen et al., 2011; Ernst, 2009). In this GIN arrangement MNCs dominate some (increasingly 'servicized') innovation phases but not all. Advanced country small and medium-sized enterprises (SMEs) control some, while SME and larger firm ecosystems in emerging markets dominate innovation in other global spaces. It would be too crude to say 'services in the West, manufacturing in the East' but that captures elements of the shift. This is because the picture is characterized by complexity and a degree of 'self-organization' in the manner of GPN displacement and GIN emergence in the global system. It happens but no 'global controller' planned it (Holland, 1998).

The paper also goes further than perspectives that rightly stress the striving of emergent economies to innovate and thereby displace current incumbents (Mudambi, 2008). It does this by showing that in ICT this has become an accomplished fact. New networks undermine the linear notions of GVC and GPN in this complex global rearrangement. As noted, from this perspective there is no single 'creative heart' but rather a distributed intelligence. Accordingly, a complexity viewpoint questions the existence of a single 'global controller' omnisciently directing events from on high. Geographical dispersion of the broad kind in focus here was observed early for mobile handsets (Mudambi, 2007) but as we have seen already a 'smartphone' or 'tablet' bundles more distributed modules than any mobile telephony handset. Stan Shih, former CEO of $A C E R$, in 1992 coined the term 'smiling curve' (see below) to capture both the geographical distribution and the innovation intensity of modularization in terms of its unequal value return (Mudambi, 2007). This is changing such that some lower parts of the value curve increase their value realisation (Taiwan, S. Korea) while newer entrants (China) occupy the lowest positions. Value constellations thus characterize new products and the underlying TIS arrangements in the ICT GIN (Normann \& Ramirez, 1993). In other words, modularization, which began with the vertical disintegration of the chip industry (Grove, 1996) has been a significant driver of both the GPN but more extensively the GIN for ICT. In brief, this paper testifies to a shift back a little from firm to regionalized system in comprehension of the complex changes now under way. Accordingly, it concurs with the following observation:

'In the early development of the international business field, the focus of attention moved from the country level to the firm level...............The locational composition of the international network for knowledge sourcing of a given MNE depends upon the extent of institutional compatibility between the locations in which the MNE is active. This compatibility between locations in turn affects the capacity of the MNE to become an insider in local business systems, and to influence the local institutional environment (Cantwell, 2009)

Except that, the paper pushes further to say that, for some activities in the implementation of innovative elements of the ultimate product service, the influence has moved from inside certain innovative ecosystems outward to the MNC.

Such dynamism is not unusual in the ICT industry. Accordingly, once-important flagship firms like Motorola, formerly a global innovator and market leader, first, 
utilised the Google Android software platform for its handsets, before its struggling Motorola Mobile arm was itself acquired by Google. Other former top competitors that succumbed to faster-moving rivals include Ericsson, Palm, Siemens and Alcatel. Ericsson, which competed with Motorola and Nokia in the top three throughout the 1990s, combined its phone unit with that of Sony in 2001 to help regain lost market share; SonyEricsson slipped to sixth before its break-up in late 2011. Siemens and Alcatel, both in the top five a decade ago, never recovered from market-share losses and ended up selling or giving their mobile-phone businesses to Asian rivals. Motorola's handset business, which occupied second spot globally as recently as 2007, fell to seventh, and was spun off in early 2011 from the rest of the company in a bid to recover. Motorola Mobility (in 2011 acquired by Google) offered tablet devices with seven- and ten-inch screens. In the increasingly crowded tablet market, the larger device would compete unsuccessfully with the iPad and the smaller device would compete similarly with RIM's planned PlayBook tablet and Samsung's Galaxy Tab, which also uses Android.

As can clearly be seen, the ICT inside these convergent communication devices is now a cheaply produced, commodified technological input (chips, PCBs etc.) assembled in locations such as Shenzhen, China by giant overseas contract manufacturers such Foxconn and Mediatek of Taiwan. The key value of the products shipped lies almost entirely in the software, system and services supplied on smartphones and the innovative applications ('apps') increasingly produced by start-up businesses in the West. These constitute the corners of the 'smiling curve' GIN value-added line as described in Chen \& Wen (2011; Fig. 1). Important here are the higher value segments of the GIN, where advanced services like design and marketing are concentrated in the West, compared to the lower value manufacturing segments, largely in Asian territorial innovation systems (TIS). The importance of TIS is further discussed in section below. Allocation of TIS to regions and countries is implemented in "Outline of Complex System Adaptation in Global ICT".

In the paper, an account is given of the main innovative elements of this rapidly evolving industry, demonstrating how the division of labor among tasks has been distributed, but narrowly and in territorial innovation systems (TIS), over the globe. In

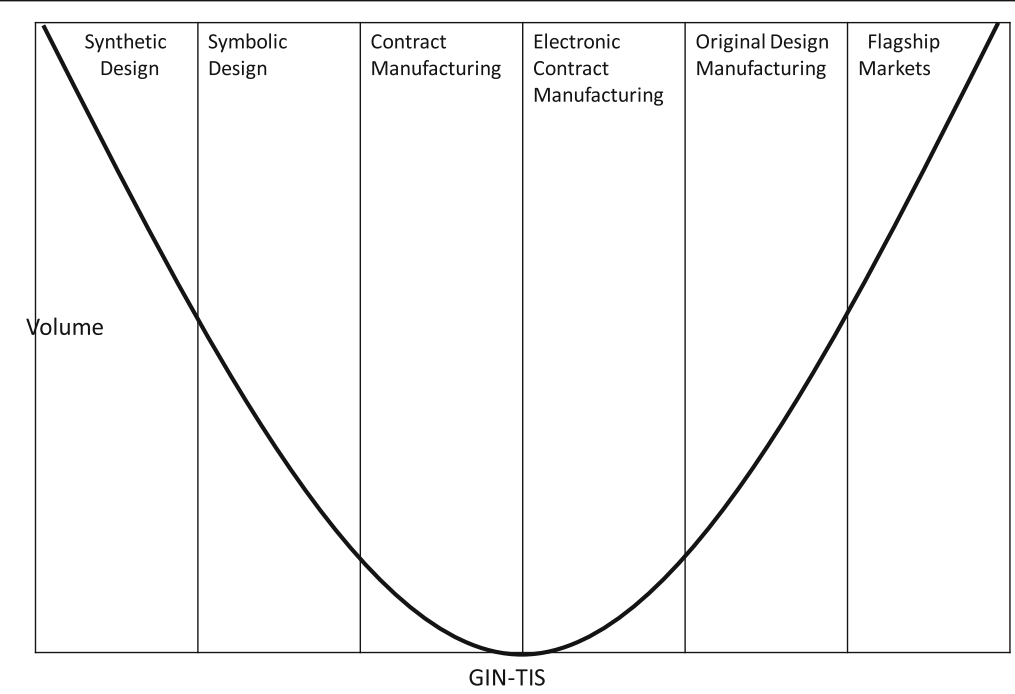

Fig. 1 The 'Smiling Curve' of ICT Global Value Segments. Source: S. Shih, ACER 
this, the West retains the leading edge in software, systems, services to some extent, and 'apps' but Asia Pacific dominates hardware and in South Korea hardware engineering and design where there remain innovative applications to be exploited. Thereafter, a different account is given of the utilization of commoditized computation using ICT componentry in new applications that frequently utilise ICT technologies as derived parts of a new demand for ICT enabled devices in new markets. These accounts are preceded by a theoretical section which frames the evolutionary economic geographyinfluenced analysis of global ICT in relation to innovation interactions between the West and Asia Pacific.

\section{A note on research methodology}

Because of the nature of the complex adaptive systems that are the object of analysis of evolutionary complexity theory (ECT) it is in social scientific terms characterized by a distinctive but recognizable research design and methodology. This differentiates it for the present from methodologies typically deployed in complexity analyses of physicochemical or biological processes. These involve either quantitative analyses of billions of data runs, or large scale or number simulations of real-world processes like evolution utilising, for example, cellular automata (Mitchell, 2009). By contrast, the approach adopted here is the following. To deepen understanding of an emergent, complex and evolving environment involves adopting 'co-creating' methods (Kingdom, 1984) or as Eve Mitleton-Kelly puts it:

'..........complex problems cannot be explained using mono-causal explanations, that is why it is essential to identify the multiple interacting dimensions, which together create and re-create the problem-space. These multiple causalities coevolve and change the problem space. Any 'solution' must therefore also coevolve, hence the importance of co-creating an endogenous enabling environment that will coevolve with its exogenous broader social ecosystem (Mitleton-Kelly, 2011, 3)

Moreover, while this may seem daunting, Mitleton-Kelly's (2011) key conclusion regarding methodology to understand co-evolving system or network processes, which is also routinely utilised in innovation, governance and policy research (see, for example, is as follows:

'.......the use of complexity principles and the methodology can be used quite effectively by non-academics to identify the problem-space, with only some basic training and introduction to the theory, as most of the methods are familiar. It is their combination and particular perspective which is different, as well as the use of the theory as an explanatory framework....' (Mitleton-Kelly, 2011, 2)

Her preferred methods in five different projects described in the quoted paper were semi-structured interviews with representative firms and support agencies, individual and group analyses and a small number of reflect-back workshops. This methodology is closely aligned with that deployed typically in regional innovation systems (RIS) research (see, for example, Tödtling \& Trippl, 2005; Trippl, 2011). In summary, this involves selection of leading innovative industries, with assistance of secondary databases; selection of representatively scaled and proportioned regional firms by industry; administration of innovation-focused questionnaires; similar process for representative regional innovation intermediaries (e.g. public - appropriate government departments, 
development agencies, innovation agencies; private - venture capitalists, management consultants, incubators); selection of illustrative respondents for face-to-face interview; analysis, modelling and reflect-back workshop presentations of data and results.

The TIS in this paper is an open system composed of knowledge exploration and exploitation sub-systems. The former is a mostly public 'regime', the latter a predominantly private technological paradigm or mix of paradigms. The sub-systems meet at the intermediaries that link them, such as knowledge transfer, intellectual property and venture capital actors (Cooke et al., 2000).

Clearly, the RIS approach is both quantitative and qualitative whereas the evolutionary complexity theory (ECT) approach is largely qualitative. The latter is considerably cheaper; for example the nine region innovation systems project described in Cooke, Boekholt \& Tödtling (2000) cost the European Union some $€ 1$ million at 1996-8 prices. Accordingly, given the global scale of the research task essayed in this paper, the latter approach was inspirational but the former was the more practical. The methodology adopted was thus dependent on semi-structured interviews with representative firms and support agencies, individual and group analyses and a small number of reflect-back workshops. First, key ICT ecosystems were identified. For example, in Europe this involved secondary documentation and data analysis to identify these, then meetings were set up with key firms and agencies (e.g. cluster manager) where semistructured interviews were held involving two interviewers. Individual and group analyses were then conducted for interpretation and triangulation purposes. Finally, in the European-based research, which also involved inquiry into global shifts in ICT, results were reported to two reflect-back workshops with ICT firm and agency representatives and respondents from the regional ecosystems. In Asia and north America, ICT research documentation was accessed and expert interviews conducted with knowledgeable respondents from industry, government or academe as appropriate and available. On most occasions reflect-back opportunities occurred at workshops and seminars where forerunners of this paper were presented. Although dualistic, with more formalised and direct face-to-face firm and agency interviewing in the first part and co-present, but for practical reasons, more distanced interactions in the second, the results nevertheless (after Geertz, 1973) provide rich, thick descriptions of real phenomena and action instances, theory testing and facilitation of communication to governance, managerial and academic audiences (Birkinshaw et al., 2011; see also Marschan-Piekkari \& Welch, 2004).

\section{Theoretical perspectives on GVC-GPN-GIN interactions in Asia Pacific's ICT rise}

In this section the paper indicates the theoretical nature and intent of the account of shifting global relational geographies in ICT. Of course, as Juarrero (2000) puts it, the observer of any complex phenomenon is also an influence upon that phenomenon and its representation to others. Metaphor is ubiquitous in science from DNA to GIN. So the paper is using theory as all science does to communicate the deeper simplicity underlying what can appear a chaotic and certainly complex reality. Fundamentally, there was, for many years, a single metaphor for globalisation in relation to industrial organisation. Accordingly, in the 1990s, the discourse of Global Value Chains (GVC) was being worked out (Fig. 2). This displayed a linear, mostly hierarchical set of 


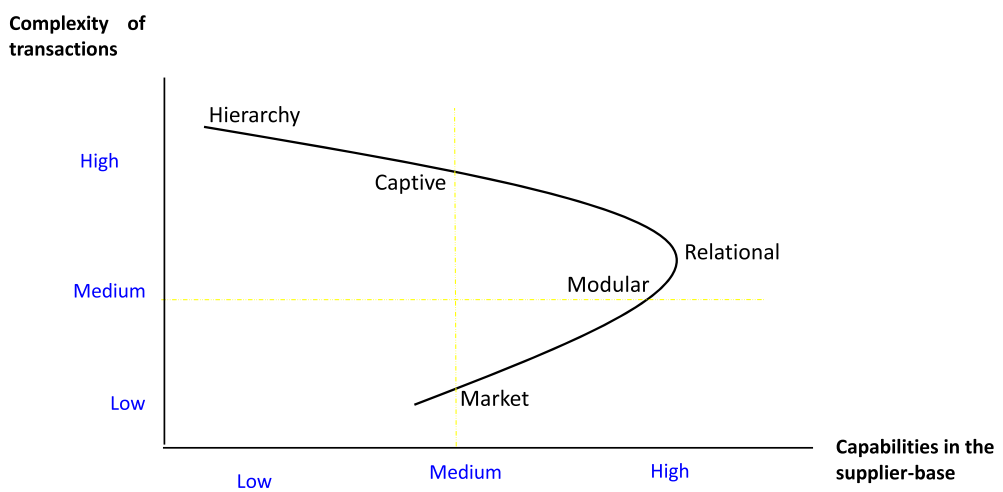

Fig. 2 The networking curve for types of global value chain performance. Source: Elola, A, Aranguren, M. \& Valdaliso, J. (2011)

relationships, held to apply more or less similarly for all globalizing industry customersupplier relations, irrespective of content or technology. Clearly this monocular perspective could not continue and it gradually gave way to two conceptual developments: the first concerned Global Value Chains 2.0; the second, GPN. GVC 2.0 conceived how five different kinds of relationships might be chosen to understand the interactions among incumbents in a variety of industries (Gereffi et al., 2005). This yields a different kind of 'curve' to that denoted by the 'smiling (value) curve' shown in Figs. 1 and 4. Gereffi et al. (2005, 84-86) developed a theory of value chain governance based on three factors: the complexity of the knowledge transfer required to sustain a particular transaction; the extent to which this knowledge could be codified; and the suppliers' capabilities in relation to such transactions. On the basis of these three factors, they identified five different governance patterns:

1) market-based chains characterized by low complexity of transactions, simple and easily codified product specifications and capable potential suppliers,

2) modular chains characterized by highly codified links simplified by technical standards, where suppliers make products to a customer's specifications and take full responsibility for process technology,

3) relational chains characterized by complex transactions and highly idiosyncratic relationships which are difficult and time-consuming to re-establish with new value chain partners,

4) captive chains characterized by suppliers with low capabilities, dependent on larger, dominant buyers, who exert a high degree of monitoring and control,

5) hierarchy implying vertical integration when transactions are complex and not easy to codify and the competence of suppliers is low.

Drawing on their model and on some other works that address the relationship between transaction costs and firms' capabilities over time Elola et al., (2011) usefully depicted the relationship between the complexity of transactions and the suppliers' capabilities and its several different outcomes according to types of value chains depicted in Fig. 1. The main advantage of this 'networking curve' is that it allows us to show the relative position of each value chain type regarding the others. 
However, this figure focuses exclusively on firms rather than encompassing the role played by other institutions. It also addresses exclusively the 'optimization problem' of the global value chain at a particular time with a given level of complexity of transactions and capabilities in the supply base. However, it does not address how evolution over time allows system adaptation in the 'complexity science' sense (Kauffman, 2008). Thus technological and institutional changes can affect both the complexity of transactions and the capabilities in the supply base. Accordingly, what was something of a weakness in the first mono-linear version of GVC, namely a failure to account for nonfirm governance that can of course be deeply-imbricated in economic relations, was carried over to the multi-linear version.

Dissatisfaction with the narrowness of this focus and continuing inattention to important institutional elements of the 'emergent' globalisation phenomenon, led to the elaboration of a GPN framework. Yeung (2011) defines global production networks as the globally co-ordinated interconnected practices of firms and non-firm institutions whereby goods and services are produced and distributed. Such networks co-ordinate firms into relations that may cross organizational boundaries between equity and nonequity form. Further, they integrate territorial economies with considerable implications for their developmental potential. Accordingly, in a TIS, firm-centred production networks inscribed in their paradigm or combination of distinctive technological 'paradigms' connect to territorial 'regime' settings in which they are also embedded. The process is interestingly complex since 'regimes' are territorially specific while production networks are global. Hence, global production networks interact with territorial 'regimes' in distinctive ways. They are influenced by incentive, subsidy and regulatory elements of their 'regime' as well as local 'conventions' (Sunley, 2011) that contribute to network interactions making them fundamentally relational.

Clearly, this is an improvement on the 'governance-lite' GVC approach where control is exerted by multinationals (MNCs) in the main. However, MNCs remain more than significant puppeteers, even in the GPN perspective. Accordingly Gereffi et al. (2005)and GPN suffer from retention of both a (modified) linear view of the phenomenonunder inspectionand an over-emphasis on production in their analyses. This is reminiscent of an older territorial tradition represented in the work of Vernon (1966) whose emphasis on production in micro-economic dynamics more or less blinded him to the importance of innovation in changing the locational impulse of regional and global economic development (Tichy, 2011). Accordingly, both GVC and GPN approaches to integrating territorial development relations suffer from a failure to appreciate nonlinearity in such interactions and the relative rise of innovation as a competitive weapon in comparison with an earlier 'productivist' norm emanating from a short period of knowledge leadership by Western MNCs. The GIN approach eschews both linearity and Occidentalist knowledge leadership elements of the new relational space of global innovation. This is particularly pronounced in ICT where we shall see Asian innovation, in particular, leaving the West behind in some, if not yet all, developmental stages.

The academic originator of GIN, Chen (2004) ascribes considerable influence to Taiwan's TIS in the development of its role as an innovation platform in the contemporary GIN. By extension, he ascribes similar force to that of South Korea in assisting Samsung and $L G$ to leading roles in technologies like flat panel display, AMOLED touch- 
screens and DRAM integrated circuits. In Taiwan's case, assistance occurred in the huge investment in constructing the world's leading silicon foundry. But assisting Taiwanese SMEs and emerging ecosystem leaders to forge partnerships with global MNCs like Mitsubishi, Sharp, IBM, Philips, and Toshiba then subsequently acquire their divesting technology divisions was as important. In this the role of Taiwan's TIS, especially in the form of Taiwan's Industrial Technology Research Institute (ITRI) was of crucial importance. In South Korea that role was played by what is now the Ministry for Knowledge Economy and agencies like the Korean Institute for Advancement of Technology. Singapore similarly had the Agency for Science Technology \& Research. Such agencies are not TISs in their own right but they knit together a sub-system of innovative firms with knowledge support sub-system intermediaries, agencies, ministries and universities. Accordingly, while not able to predict the future, such combined knowledge assets in geographical proximity allow 'fortune to favour the prepared mind'. But TIS must be constantly vigilant as the GPN experience of Singapore suggests. There an alliance among the Singapore state, Seagate and Western Digital gave Singapore dominance of the PC-led hard disk drive production chain. In the late 1990s-early 2000s that must have seemed like grasping a key part of the high end of the value chain. But PCs are now no longer hegemonic in the face of 'tablets' and HDD is no longer hegemonic in the face of 'flash' memory and 'cloud' computing. Thus without anticipatory innovation support, firms alone are vulnerable to unexpected changes in the core of their technological being and state strategies may founder accordingly. In Singapore's sub-regional GPN nowadays Penang in Malaysia is also losing its ICT position as are Thailand and the Philippines as the preceding GPN system transitions into a GIN-TIS set-up. For some specific components and peripherals, the partly vulnerable locations $1-3$ are as follows:

1. Monitors Europe and Asia (Phillips, Nokia, Samsung, Sony, ACER)

2. PCBs Asia and Eastern Europe (Sanmina- Singapore/Malaysia, Celestica-Dongguan, China)

3. Disk Drives Asia, mainly Singapore (Seagate/Maxtor-Suzhou, Western DigitalShenzhen)

4. Box builds Asia and Eastern Europe (Hon Hai/Foxteq-Foxconn; Taiwan/China)

5. Chassis Asia and Eastern Europe (Hon Hai/Foxteq-Foxconn; Taiwan/China)

Taiwan-based Foxconn Technology Group, which includes Hon Hai Precision Industry, supplies a constellation of global brands including Nokia, HP, Apple and Dell. Apple is also supplied with touch-screens by Wintek of Taiwan, operating out of Suzhou, China. Most 'world factory' production by Foxconn comes from its plants in Shenzhen, in the Pearl River Delta area, one of the three major Chinese coastal manufacturing hubs, along with the Yangtze River delta area around Shanghai and near Beijing. It has now opened inland at Chengdu, Szechuan province, $1600 \mathrm{~km}$ (1000 miles) from Shenzhen, where wages are lower and workers more plentiful, keeping mostly higher-value, engineering and R\&D work in China's coastal areas. Foxconn will have as many as 1.3 million workers in China by the end of 2011, up from 920,000 in 2010.

This kind of tough global competition involving significant shocks to traditional hardware manufacturers as Asian competitors rise, affecting inland populations soon to 
be recruited to the world's largest factories, and to managements charged with charting new ways forward into knowledge-intensive services, occurs far more swiftly than it did when the GVC was first being mapped out. It demands a new 'complexity geography' of 'complex adaptive systems' that can capture the destabilisation and re-stabilisation effects of such massive and significant moves. In only some ten years the 'world factory' model of massively scaled production platforms in locations like Shenzhen, on the one hand, and monopolistic embedded software and systems platforms like Cambridge (UK) for chip design or Malmö, Sweden, Waterloo (Canada) and Silicon Valley for smartphone 'apps' have reconfigured the global production framework from a 'diffused network/cluster' model to a more focused 'distributed platforms' one. Notable in Silicon Valley is the integration of 'apps' micro-businesses in the localised Kleiner Perkins venture capital 'keiretsu' or ecosystem (the \$200 million iFund) which supplies iPad 'apps' at Apple's 'App Store' (Graham, 2010).

\section{The geographies of GIN/TIS co-location}

The GIN seems fairly straightforwardly to be replacing the GVC and GPN for ICT with new firm entries emerging endogenously from key TIS locations in that evolution (Chen 2004). While Chen \& Wen (2011) make this point forcefully, drawing attention to the manner in which Taiwan's components flagships out-innovated Western incumbents in 'chipstack' innovation, more telling is the transformation in the chip content of the early Apple iPhone 3G and most recent iPhone 4S. The authors show that of the seventeen key components in the iPhone 3G of 2007 none was Taiwanese in origin. However, by 2011, one core power/memory filter chip was produced by Taiwanese firm TXC, while firms such as Largan Precision supplied the camera, Wintek and TKD the touchpanel, Hon Hai various EMS (electronic manufacturing services; see Figs. 1 and 4) and its China subsidiary FoxConn flexible circuits, connectors and casings. As noted earlier, South Korea, notably Samsung, supplied the iPhone 4Sapplication processor, DDR DRAM memory integrated circuit and, with its joint venture partner Toshiba, the flash memory chip for the iPhone 4S. Casualties of this transition to GIN for the iPhone $4 \mathrm{~S}$ included National Semiconductor, ST Microelectronics, Broadcom, SST and Wolfsonall from Europe or the US. The Taiwanese and South Korean TIS arrangements are distinctive but successful. Taiwan is well-known for its endogenous SME ecosystem that has been well-served, as described above, by ITRI, the investment in its silicon foundry that brought learning opportunities from all chipmakers in the world who had to use it, and acquisition of corporate divestments, like IBM's PC assembly plants which were sold to Sanmina-SCI. South Korea's TIS is hierarchical rather than heterarchical, as in Taiwan. The state's agencies reveal a track record of working closely with domestic ICT flagships like Samsung and $L G$, even enforcing reorganizations of their product lines if necessary and facilitating partnerships with foreign MNCs for in new innovation platforms (e.g. flat panel displays and touchscreens) as we shall see below.

\section{The upper reaches of the 'smiling curve': Skåne region, Sweden}

Let us look first at the regional TIS for mobile telephony in southern Sweden's Skåne region. Large firms like Ericsson and Ericsson Mobile, later SonyEricsson, used to animate this region's ICT paradigm, but increasingly global competition led to their 
initiation of 'open innovation' SME and GIN activity. Such engagement was carefully promoted by the regional development agency. Included here are various localised cluster initiatives: first, for mobile telephony ('Mobile Heights'); second, new media ('Media Evolution'); and third the Skåne film industry (Wallander detective films), including computer gaming. These nowadays constitute the core of a globally interactive regional 'Convergent Media' platform. During the 2000s, the Swedish market and production home base were invaded by rapidly expanding Asian smartphone producers from South Korea (Samsung), Taiwan (HTC) and China (Huawei). This led SonyEricsson to begin reducing shipments of hardware and focusing more on managing global network services to mobile telephony suppliers such as Telenord and Telia. This led to Telia itself cutting employment after the mid-2000s, also filing no more patents. Finally, SonyEricsson disbanded in late 2011. ST Ericsson, the telephony infrastructure arm of the Ericsson Group also seems vulnerable as a stand-alone company, Chinese telecoms flagship Huawei being a likely suitor. Global rivalry in markets is one thing but in core mobile telephony design and contract assembly SonyEricsson mostly feared Huawei, which located a third Swedish research centre in Lund, Skåne for the development of basic components for mobile phones. This augmented their earlier locations at Kista Science Park in Stockholm and Gothenburg, together employing 250 engineers. In Lund SonyEricsson cutbacks had made further hundreds of qualified engineers available. Huawei spans the telecoms range from base stations to mobile Internet modems and its own telephone handsets. Open innovation came too late even though Skåne TIS clusters had spawned quality entrepreneurial firms such as user-interface maker The Astonishing Tribe (TAT), acquired by RIM (BlackBerry), the similarly troubled Canadian smartphone flagship and Polar Rose, another start-up with a facial recognition programme that linked into Facebook photos, which was bought by Apple for \$29 million, both in late 2010 .

\section{Nokia, Finland}

In January 2008, Nokia announced it was closing its factory in Bochum, Germany. Altogether, some 4300 workers lost their jobs (2300 workers employed directly by Nokia, another 1000 temporary workers, and a further 1000 working at suppliers to Nokia). Production was shifted to a new factory in the Romanian city of Cluj. But already by September 2011 Nokia announced that it would be transferring the manufacturing of the low-end phones made in Cluj to larger factories in China and South Korea, where production costs and economies of scale were more favourable. The Cluj factory was subsequently closed in late 2011. But this was almost certainly too little, too late. Nokia's problems lay in a cognitive lock-in, on the one hand and a failure to develop the necessary internal and external 'radar' for effective foresight, on the other. Myopia meant Nokia failed purposefully to anticipate 'convergence' trends in the industry. Such attentiveness would have shown mobile telephony, the company's core competence, to have become possibly the least important function on a contemporary 'smartphone'.

Thus for some twenty years Nokia had enjoyed being the undisputed global market leader in mobile handsets. It is, nevertheless, the view of industry experts like Jon Andersson (2011) that this situation ended with the arrival on the market in 2007 of 
Apple's smartphone - iPhone, iPod and related iTune platform for music and applications ('apps') of all kinds. Apple and Google's (Android) mobile platforms nowadays attract a global network of developers the main focus of whose innovation is the creation of new applications ('apps'). In addition, as chips for mobile handsets became more and more powerful the mobile handset changed from a mobile phone to a mini computer with increasing possibilities for software applications ranging from banking to gaming and city maps. This explains why the physical mobile handset is today the least important part of a mobile phone and where the least added value accrues. Nokia got lockedin to an operating system - Symbian - that was once state of the art and retains robust functionality but lacks the flexibility for convergence of the kind exploited by Apple and Google Android. It acquired this Cambridge (UK)-based consortium operating system in 1999 which reinforced Nokia's telephony-led path dependence. Nokia's early successes were closely integrated with the activities of Finland's TIS, led by innovation and research agencies Tekes and VTT but its spectacular growth led it to undervalue its TIS, both nationally and regionally, where managers of innovation agencies, at the outset attractive co-creation partners, were sacrificed for the most important corporate customers.

For the first time in its history the Finnish firm appointed a non-Finn as CEO, choosing Canadian former Microsoft executive Stephen Elop in 2010. In early 2011, Elop referred to Nokia as a 'burning platform' in recognition of its failure to keep up with the 'smartphone apps' generation. Elop's announcement admitted that Nokia had been comprehensively out-manoeuvred by Apple's iOS and Google's Android (2009) platforms. Nokia's profits were eroding at 20\% per quarter in late-2010/early-2011 and it still at that time had no competitor platform to those of the two global leaders. A tieup with Microsoft meant its Windows Phone 7 operating system now had a muchneeded platform company on which its system product could, in principle, reside. However, with Nokia's smartphone market share halving in two years from $47 \%$ (end 2009) to $38 \%$ (end 2010) and 24\% (end 2011), its future as a global competitor was not helped by industry opinion that its new Microsoft-powered Lumia 800 smartphone was 'disappointing' (Naughton, 2011). Microsoft-powered devices had 5\% global market share at end-2011 (LMS, 2011).By late 2011 not only had Nokia been closing relatively new cheaper labor zone production facilities but it had announced a $40 \%$ cut in its global R\&D payroll. Earlier downsizing in software design had resulted in thousands of Symbian-related software developers being transferred to consulting and outsourcing firm Accenture who hired eight hundred in Finland alone. Some 2300 employees from China, Finland, India, the United Kingdom and the United States (a good portion of the ICT GIN) were to transfer to Accenture by 2016.

\section{NorCom, Aalborg, Denmark}

This is a brief sketch of regional cluster rise and demise in a sphere of mobile telephony addressed above in relation to the early days of this pioneering technology (Stoerring \& Dalum, 2007). The key lay in the Nordic communication standard eventually being adopted by the EU, giving European cellular service providers the advantage of a uniform GSM standard before anywhere else in the world, notably the USA, could achieve this. Infrastructure electronics was a centre of research and teaching excellence 
in the University of Aalborg. Research showed that this was because of the region's fishing tradition and early innovation in ship-to-shore communication with local firms specialising in this technology that grew with the emergent field. But the NorCom cluster itself grew because of proximity to Aalborg University's NOVI science park and research expertise in radio communications that readily translated into spinout companies. By the 1990s these had mostly been acquired by MNCs like Texas Instruments, Motorola, Siemens and Amstrad alongside smaller but 'born global' ICT firms like Cambridge Silicon Radio (CSR). This is nowadays one of the mainstays of Cambridge's toe-hold on the ICT GIN through its expertise in 'fabless' chip design, particularly for 'smartphones'. The MNCs quarried the knowledge base and one by one they all left, making hundreds of engineers jobless each time. From this some new start-ups emerged but the base station infrastructure had become a commodity item sold into, for example, the Nordic and UK markets by the likes of Huawei. NorCom is by now an undifferentiated element in a diffused software and systems design ecosystem of niche businesses in the broader north Jutland region (Reinau, 2010).

\section{California: home of the 'smartphone'}

Whereas the Nordic story is one of decline, the Californian is one of replacing them at the design and marketing peaks of the 'smiling curve' of value realisation in contemporary ICT. The global power of the smartphone 'apps' platform is testified to in the following narrative. Thus Apple and Google in 2011 ended a 'phoney war' to engage in an all-out contest, the victor in which would be the one attracting the most desirable apps for the smartphone and tablet platforms that used their proprietary operating systems. Industry experts expected Google to prevail, which in 2011 it did in terms of market share, because of its open source and open innovation model. This meant the quantity (if not the quality) available on its Android system with $46 \%$ global market share by late-2011 ensured it overtook Apple's 28\% smartphone share (LMS, 2011). A counterargument favouring Apple was that 'apps' entrepreneurs interested in profits rather than experiencing the glory of publication on Google would prefer Apple's closed innovation model (iOS system) because of its superior IPR regime. This allows for contractual appropriation by suppliers of income streams (e.g. digital newsprint). Apple's newsprint 'app' scheme charged 30\% of subscription fees and disallowed data sharing (e.g. subscriber addresses). Google's model charged publishers only $10 \%$ of subscription fees and subscriber information was passed along. It is basically a scope versus scale contest in which Apple's App Store runs on tight control, high vetting and censoring of apps, while inducing high customer loyalty. Google's approach is more liberal but also less quality-minded since Android has been an open source project from the start. Thus customers buy Android through buying an HTC, Huawei, Samsung or LG smartphone rather than from Google itself. Global Android sales were also pushed up by extremely low cost devices including a ZTE Android device that is sold for just \$20 in China. Contrariwise, to access its IPR assets Google in 2011 acquired Motorola Mobile whose Droid 4 device competed with Samsung's Galaxy Nexus powered by its new Android 4.0 Ice Cream operating system.It is worth bearing in mind that while key 'apps' customers (Apple especially) are based in California, many more 'apps' start-ups are also located elsewhere, optimizing on 'related variety' among software, system design 
and creative 'search' integration. Similar platforms exist in London's 'silicon roundabout', Malmö's Western Harbour, Toronto's downtown creative district and other places, both in Canada (e.g. Ottawa; Waterloo) and elsewhere (e.g. New York's Silicon Alley).

\section{Cambridge, UK software and systems design excellence}

In GINs an intriguing issue arising concerns the importance of (possibly small) firms as system integrators in or among innovative clusters. In an industrial world characterized by lean production, open innovation and modular clusters (as Andy Grove, former CEO of Intel refers; Grove, 1996) such 'hub firms' become crucial actors. They play major roles in aggregating 'relatedness' of knowledge, business model and industry. Clearly, the question of how there might be an interface or complementarity between what firms do regarding orchestration of a value chain changes over time. One of Cambridge's software successes is logistics software from firms like 2011 IPO Ubisense; another is customer data quality. Thus in 2011 Datanomic, a leading provider of customer data quality software and related applications for risk and compliance screeningwas acquired by Oracle for just $\$ 80$ million, while later in the year data-mining software flagship Autonomy was purchased for $\$ 10$ billion by Hewlett Packard and seen as an indicator of HP's then policy of seeking to leave hardware and develop as a services firm with the mooted sale of Compaq. However, a palace revolution in HP removed CEO Apotheker, architect of this strategy and such a move is now on hold. We may understand how transformative systems integration became by noting how crucial the role of modularised system and software services and products became in ICT even in the 1990s by referring to Grove's diagram explaining that historic shift in industry organisation from 'vertical silos' to 'modular clusters' in Fig. 3 (right side).

Clearly, Cambridge has a relatively small but crucial role in the contemporary smartphone and tablet GIN. It is a significant centre for ICT research and innovation, notably through its 'fabless' chip design companies such as ARM Holdings and CSR (Cambridge Silicon Radio). These supply some 99\% of smartphone chip designs that are subsequently turned into componentry by the firms discussed earlier as suppliers to Apple's evolving generations of smartphones. ARM's new strategy is to design processors that power the networks that run smartphones as it steps up competition with Intel in a \$9billion global market.ARM already partners Hewlett Packard to create chips for computer servers; accordingly the same processor will also be directed at the base

\begin{tabular}{|c|c|c|c|c|c|c|c|c|c|c|}
\hline \multicolumn{4}{|c|}{ 'Vertical Silos' (circa 1980) } & & \multicolumn{6}{|c|}{ 'Modular Cluster' (circa 1995) } \\
\hline IBM & DEC & $\begin{array}{l}\text { Sperry } \\
\text { Univac }\end{array}$ & Wang & \multirow{6}{*}{$\begin{array}{l}\text { Sales and Distribution } \\
\text { Application Software } \\
\text { Operating System } \\
\text { Computer } \\
\text { Chips }\end{array}$} & & & & & & \\
\hline Sales & and & Distri- & bution & & \multicolumn{2}{|c|}{ Retail Stores } & Superstores & Dealers & \multicolumn{2}{|c|}{ Mail Order } \\
\hline Appli- & cation & Soft- & ware & & Word & Word Perfect & \multicolumn{4}{|c|}{ etc. } \\
\hline Oper- & ating & Sys- & tem & & \multicolumn{2}{|c|}{ DOS and Windows } & $\mathrm{OS} / 2$ & Mac & \multicolumn{2}{|c|}{ UNIX } \\
\hline Co- & mp- & ut- & er & & & Compaq & Dell & Packard Bell & IBM & etc. \\
\hline C & $\mathrm{h}$ & i & ps & & & Architecture & Motorola & & & \\
\hline
\end{tabular}

Fig. 3 Vertical to Horizontal Transition in ICT. Source: after Grove, 1996 
stations and wireless network equipment which are intended to embody the $A R M$ architecture. ARM's low-power semiconductor blueprints are increasingly found in larger devices including tablets and other mobile computers as the company competes with Intel, the world's largest semiconductor maker. ARM will use its faster processor in server farms to help companies rein in energy costs. In connection with such ecofriendly chip designs, US company LSI signed a licensing agreement to use ARM's faster processor in mobile broadband networks, while Texas Instruments is also using the $A R M$ blueprint to build chips for base-station infrastructure. ARM's smaller compatriot $C S R$ also occupies a high point on the 'smiling curve' as an implementer of analogue designs for Bluetooth integrated circuits. As the world's leading supplier (ten million so far) of Bluetooth silicon CSR achieved its position by designing products that put a full 2.4GHz RF front-end on the same chip as the digital baseband circuitry. Successive generations of product have seen the company add flash memory, ROM and even a digital signal processor to its single-chip Bluetooth devices to support a variety of market needs.

\section{The Asian mid-and lower reaches of the 'smiling curve': South Korea}

South Korea's presence relatively high up the 'smiling curve' of value creation in the global innovation network for ICT rests on chip, touchscreen and flat panel display innovation. One of the fields 'picked as a winner' by the national innovation system was, as with Taiwan, Flat Panel Display (FPD) technology. In 1995 Asan-Tangiiung was selected as a site where Samsung and a further 153 firms, including three Samsung affiliates would locate as an LCD (Liquid Crystal Display) megacentre. Nowadays Samsung controls $45 \%$ of the South Korean market and 17\% of the world market from this location. More than a decade later, LCD and plasma screens generally have given way to LED (Light Emitting Diode) and specifically AMOLED (Active Matrix Organic LED) technology because far less energy-intensive when powered up as TV or other kinds of FPD screens.

With Asan-Tangjiung as Samsung's fiefdom, the South Korean government in 2002 selected Paju as the site for a competitor FPD development for LG Display, successor company to the former LG-Philips joint venture. This megacentre began with eighty firms, including four $L G$ affiliates and two foreign firms. These were Nippon Electric Glass (NEG) to provide LCD glass substrates, some $20 \%$ of product added value, and Sony in partnership with Samsung for early LCD technology transfer. Close to the demilitarised zone with North Korea, Paju has grown enormously in population and GDP as the megacentre itself has grown. A further Gyeonggi province mini-centre supplying both Samsung and $L G$ hosts a further group of foreign firms of consequence to South Korea's FPD industry, including Asahi, NEG and Hoya from Japan and Schott from Germany. The role of the state was significant in these developments in declaring Asan-Tangjiung an official Company Town Project and relaxing planning control by the Seoul SMSA to facilitate the Paju complex. This exemplifies the directional manner in which the national innovation system swiftly translates policy into reality, in this case close to the purlieus of the national capital Seoul (Lee, 2011).

This proved a strategic industry into which to make an intervention by the TIS as the following demonstrates. Three upcoming trends will secure the fortunes of these 
megacentres: transparent displays, flexible displays and colour eBook-readers. Regarding transparent displays, Samsung's 46-in. touchscreen portrays pictures, movies and graphics on a window the contents of which are movable in a manner comparable to that on a smartphone. Although aimed first at the domestic market, transparent displays also allow retailers to show dynamic content on shop-windows. Other applications are in heads-up displays on car windscreens and transparent OLED notebooks. Samsung Mobile Display also leads $L G$, as it does with transparent displays, in flexible displays. These are basically bendable displays that can be rolled out of a holder like a drawer, printed on flexible materials, or wrapped around facilities (e.g. as photovoltaic panels). Finally, there is a trend towards coloured eBook readers, led by Chinese firm Hanvon, although Fujitsu was the initial innovator. Problems with quality and reliability of these more agile and flexible FPD displays are the main obstacles to their diffusion in global markets. To summarise, South Korea's insertion in the ICT GIN is a good example of a TIS-Corporate led establishment of a significant value-adding growth element in an ICT market segment requiring huge upfront innovation investments, leaving only limited competition until even larger incumbents, such as Hanvon, enter the fray.

\section{Singapore's GPN in the face of a rising GIN}

Singapore is one of the most developed territories of south-east Asia, in large measure due to adoption by its TIS of successive ICT strategies. Unlike other 'tiger' economies in the georegion, Singapore impressed its locational value for inward investment upon MNCs rather than nurturing local firms, as in Taiwan, to develop endogenous technological capabilities. This also applied to research where instead of promoting indigenous $R \& D$, Singapore relied upon MNCs to generate external economies like knowledge spillovers and knowledge transfer. This enabled an indigenous firm like $M M I$ to become a close alliance partner of Seagate, at first fulfilling expectations of technological development. In a different segment of the market, Singapore's Venture Corp supplied printers to Hewlett-Packard, from whom it was a spin-off firm, for many years. As we have noted, Hewlett-Packard has been on the verge of forsaking hardware for ICT services markets (e.g. acquisition of Autonomy, above). Singapore's locational approach earned admirers from a development perspective, especially when it involved attracting then leading edge platforms in computing such as Hard Disk Drives (HDD) and urging foreign ICT component assembly firms to divert to developing Johor and Penang in Malaysia. This was also seen as politically astute, given Singapore's asymmetry with its large neighbours who in turn were emerging in Singapore's wake. However, the legacy has turned out to be something of a lock-in from path dependent evolution based on overseas controlled computing (especially global HDD leader Seagate). A possible alternative path was endogenous control of rapidly changing global demand for notebooks, tablets and 'convergent' smartphone applications. As we have seen, these innovations are led by US MNCs Apple and Google (Android) who neither have a presence nor significant smartphone or tablet supplier relations with Singapore. The same can be said for Penang and Johor in Malaysia's similarly locked-in to desktop PC platform technology, the markets for which have been under disruptive attack from Taiwan's and increasingly China's innovative mega-clusters around Taiwanese 
OEMs like Acer, Asus and HTC, Taiwanese modular suppliers like Mediatek, Wintek and Foxconn based in China, and Chinese all-purpose telecoms corporations like Huawei and ZTE.

According to Yeung (2011) in an effort to establish Singapore as a regional R\&D and innovation hub in the global electronics industry, local firms in Singapore were encouraged to be able to access the know-how of 'modular flagship' firms in Singapore TISdesigned local clusters. Thus in the hard disk drive (HDD) industry, local precision components suppliers such as $M M I$ developed technological know-how and market expertise through their global production network (GPN) supplier relationships to global lead firms such as Seagate (in April 2011 adding Samsung HDD to its consolidated US acquisitions like Conner Peripherals, Control Data, DEC and Maxtor) and Western Digital (in 2011 acquirer of Hitachi Global Storage Technologies). Seagate and Western Digital thus have approximately half the global HDD market each; Western Digital supplies HDDs from south-east Asia to the likes of Apple and Dell while Seagate supplies Hewlett-Packard, Dell and IBM. The advent of 'cloud' computing is one important source of the de-stabilisation of HDD markets, the 2011 floods in Thailand exacerbated this, affecting Western Digital's Thai production plants and Seagate's component supplier base, both located on the Chao Phrya floodplain in Bangkok. Singapore was a global mainport for HDDs in the 1990s but lost its previous locational advantage in global HDD production networks.

\section{Taiwan's cross-straits platform with China's 'world factory'}

Of interest here is the integration in the GIN of the Taiwanese ICT sector and the role of Taiwanese R\&D performed by the firms becoming embedded within the GIN. In general, Taiwan's ICT sector is characterized by modularisation and the pursuit of OEM/ODM contracts for brand marketers or 'flagships'. Accordingly, flagships focus their own R\&D on product concept initiation and product architecture, while delegating some R\&D to Taiwan-based ODM suppliers. Such offshore collaboration results in a network form of inter-organizational, cross-border collaboration for global innovation. But, crucially, this capability is significantly enhanced by being embedded in a TIS, in the Taiwanese case facilitated by innovation agency ITRI, a dense network of other firms, large and small, university research and co-location in science and technology parks, notably Hsinchu in Taipei. Accordingly, Taiwan-based ODM suppliers typically establish separate R\&D teams to serve different customers. As a case in point, Quanta, a leading ODM supplier of netbooks has some six R\&D teams, serving different flagships for both system products and key components. The position is similar for Taiwan-based manufacturers of inverters for LCD TVs who also provide customized solutions to different flagship LCD TV companies. Moreover, Taiwan-based ODM suppliers in that part of their GIN-TIS set-up began shrinking local manufacturing and assembly operations and exploiting their offshore sites in China and elsewhere. Such GIN "decomposition of production" (Schmitz \& Strambach, 2009) or "de-linking of manufacturing and R\&D in terms of location" (Chen \& Wen, 2011) swiftly became prevailing practice. Clearly this repeats 'flagship' practice by Western and Japanese OEMS a decade or more earlier consequent upon 'modularisation' (Fig. 3). For such ODMs Taiwanese headquarters focus upon $R \& D$ and administrative functions and their 
offshore subsidiaries perform manufacturing and assembly operations. This business model, which Ernst (2009) refers to as "Asian offshoring" rests on a firm innovation governance system (the exploration 'regime' of a TIS, in our terms) and the evolution of intra-firm divisions of labour allowing domestic prototype development followed by mass production in "world factory" set-ups across the Straits of Taiwan.

In this way, Taiwanese ICT took advantage of swift TIS evolution to become a network of innovators as well as assemblers of ICT products novel to the global market. Thus Taiwanese firms supplied the top three netbook/notebook flagships (HP, Dell and Apple) as key innovators as well as suppliers of the key sub-systems, modules and parts integrated through their TIS and global logistics networks. This is evident in the practices of ODMs like Hon Hai, Quanta, Wistron and Inventec who, according to Chen \& Wen (2011) follow the 98-2 formula of global sourcing. Set by the flagship firms, this consignment system requires $98 \%$ of 'build-to-order' volume reaching end-users within two days of the order being issued. Clearly, all partners, from flagships to key suppliers and parts contractors have to collaborate closely to ensure development and design of successive generations and varieties of, for example, notebook computers or 'smartphones'. Hence, Apple's success in iPhones benefited from and was augmented by the R\&D efforts of a variety of Taiwanese ICT firms and their innovation, production and logistics networks. According to Isaacson (2011) ARM was preferred for chipset design and Taiwanese firms for innovation because Intel was 'too slow'. This illustrates the passage of what had begun as a GPN set-up from that rather linear, flagship-led production network (GPN) to the 'emergence' (in the complexity theory sense) of a move to a higher order of complexity, of a non-linear, flagship-orchestrated GIN in which the role of Taiwan's TIS and 'Asian offshoring' were crucial interlocutors in the process. The 'potential' of the TIS to innovate, because of its 'requisite variety' of creative companies, alongside its incumbents' 'connectivity' capabilities (networks, logistics, efficiency) enabled space to be compressed by time represent a milestone in GIN-TIS convergence and spatiality.

\section{Other players}

In Fig. 4 can be seen other players, more peripheral than core to the innovation leading edge in the GIN under discussion but often sharing two features: the first, as recipients in their development of significant FDI; and second their role as 'back-office' assembly, trialling and testing, adapting or checking capabilities. Approximately level with such original design manufacturers (ODMs) as Mediatek and Wintek from Taiwan are India, Israel and Ireland. India is an important research as well as back office design and testing location for outsourced software and systems implementation initiated, first, in Bangalore by western firms like Texas Instruments, IBM and Cisco Systems and more recently by Chinese telecom giants like Huawei (e.g. Huawei has its own R\&D center in Bangalore; it also sourced telecom software testing from the likes of Infosys and Mind Tree). This company is active in all spheres of telephony from traditional landline infrastructure through ground stations for cellphones to the Chinese TD-SCMDA standard, lower-end mobile phones and, increasingly, more expensive smartphones. As noted, Huawei has developed offshoring software links to Indian software companies (the former 'body shops') as well as making inroads in European markets (e.g. traditional infrastructure upgrading in the Netherlands, UK and 


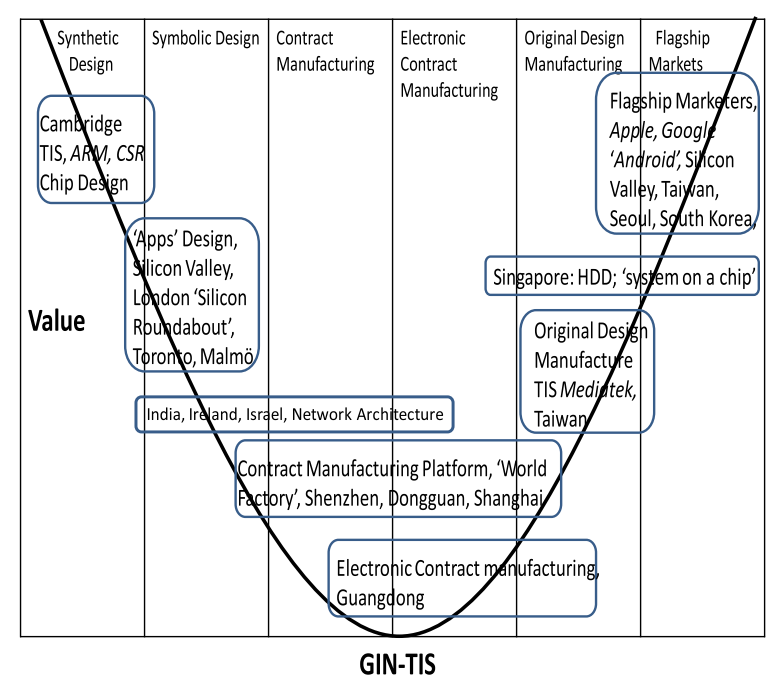

Fig. 4 'Smiling Curve' of Value in ICT Global Innovation Network (GIN). Source: Author, after Shih, S. ACER

Finland) and hiring redundant telecom engineers from Ericsson in Sweden (Lund, Gothenburg and Stockholm) and possibly in future Nokia in Finland. Israel is expert in software and systems design, especially in security software ('firewalls') and optical systems utilised in smartphones and gaming devices. Ireland hosts software development (e.g. Customer Relations Programming/ Management - CRP/CRM; SAP, Symantec), administrative functions for the likes of Google, PayPal and McAfee, and 'cloud' computing services (Hewlett- Packard, Dell).

\section{Discussion and conclusions}

This brings us, conveniently, to the final reflections on the relatively loose ties that bind the emergent GIN to a variety of TIS set-ups, signifying a further upward twist in global capabilities, shifts in centres of innovation gravity and assessment of concepts that informed thinking in this paper. The sub-text has been the global 'Convergent Media' patent wars among the flagships in contemporary ICT. The geographical and developmental narrative has focused on the deeper global, possibly 'self-organizational' system adaptations that increasingly turn knowledge exploration ninety degrees from the vertical to the horizontal dimensions as firms seek to innovate by searching adjacent 'white space' possibilities for solutions and opportunities. This ambition is for future applications away from the 'red ocean' of cut-throat competition fuelled by litigation described above into the 'bluer ocean' of shared value, social need and more 'democratic' innovation that, as the brief sojourns in Sweden, Cambridge (UK), California, S. Korea, Singapore, Taiwan and China showed have now evolved in integrated fashion.

The co-evolution of (regional) institutional regimes and related (regional) paradigms in a TIS is an extremely fruitful way to conceive of regionally and globally adaptive systems of innovation. A clear instance of this was the Skåne, Sweden region's resilience faced with multiple downturns even in its modern industries like cellular telephony. The most recent blow struck here is the termination of Ericsson's presence in mobile telephony with the purchase of the SonyEricsson brand by Sony, itself intent on emulating Apple's integrated iPlatform of digital content (Palmer \& MacCarthy, 2011).The 
cross-pollination of technology and creativity pioneered in Apple's integrated, closed platform business model contrasts vividly with the competing 'modularisation' model that underpinned Microsoft's successful era and associates with Google's Android model. But does the fact that Nokia's 'burning platform' had to be extinguished by alliance with Microsoft signify another important turn in the global ICT innovation spiral? It is the interaction of these multi-level and path dependent knowledge flows that produces innovation (Geels, 2007). Arthur (2009) calls this 'combinative evolution' in his treatise on the nature of technology and innovation. For Martin (2010) this constitutes 'path interdependence' a far more dynamic concept than 'path dependence' because it is in such 'collisions' that all innovation lies.

The world of ICT is nowadays an arena of global tournaments around technological advancements in the services and systems design software business, on the one hand, and low wage assembly platforms to bring affordable products to market, on the other. From an evolutionary perspective, there are many collisions and shocks provoking litigation and the vacating of markets by former Western European leaders in important aspects of ICT like 'Convergent Media' and, less in focus here varieties of computing. We presented a picture of how the GIN collision in one small Nordic country, Finland, that happenedonce to be a leader in mobile telephony played out in the face of rising and overwhelming upper 'smiling curve' capabilities, on the one hand, and endogenous innovation through 'technological diversification' at the lower GIN levels, on the other (Fig. 4). In most cases, as this paper has shown, the GIN-TIS integration has powered recent global ICT innovation and evolution. The paper gave limited support for the 'sense of place' advantage of MNC location (Zaheer \& Nachum, 2011) in mapping locational shift with the TIS-inflected emergence of the GIN in contemporary ICT.

\section{Acknowledgements}

Research for this paper was based on key actor interviews in Europe with secondary documentation inquiry and scholarly expert interviews in California and Asia. The author is grateful for advice and assistance in this effort from Arne Eriksson, Carin Dahl and Lennart Svensson in Sweden, Johan Wallin in Finland and Kristian Reinau in Denmark. In California, Allen Scott and Mike Moritz were invaluable guides, while in Asia my lead interlocutors were Shin-Horng Chen in Taiwan, Jun He of China Academy and S. Yaowu, Yong Sook Lee and H. Kim in Korea and Henry Yeung in Singapore. Finally thanks are due to the two anonymous referees. The usual disclaimer applies.

While Foxconn was dogged by eighteen suicides of young workers at its giant Shenzhen plant, Wintek has seen scores of young workers in the city of Suzhou poisoned by the chemical n-hexane, used to clean Apple components including iPhone touch screens. In January 2012 Apple disclosed publicly for scrutiny the names of 156 suppliers who provide $97 \%$ of its materials and manufacturing services. In March 2012, one firm on the list, Taiwan's Pegatron Corporation was reported to own a Chinese subsidiary, Kaedar Electronics of Tongxin, Shanghai accused of being a major contributor to toxic river pollution from heavy metals and a sharp rise in cancers among local residents (Lewis, 2012).

This work was supported by the DGIST R\&D Program of the Ministry of Science, ICT and Technology of Korea (16-Intelligent Auto 4).

\section{Competing interest}

The authors declare that they have no competing interests.

Ethics approval and consent to participate

No Ethical Conflict.

Received: 20 March 2017 Accepted: 25 May 2017

Published online: 22 June 2017

References

Andersson, J. (2011). Nokia's rise and relative fall: What lessons for European innovation policy? Innovation Management, 2, 30.

Arthur, B. (2009). The nature of technology. London: Penguin.

Beugelsdijk, S., McCann, P., \& Mudambi, R. (2010). Introduction: Place, space and organization-Economic geography and the multinationalenterprise. Journal of Economic Geography, 10, 485-493. 
Birkinshaw, J., Brannen, M., \& Tung, R. (2011). From a distance and generalizable to up close and grounded: Reclaiming a place for qualitative methods in international business research. Journal of International Business Studies, 42, 573-581.

Buckley, P., \& Ghauri, P. (2004). Globalization, economic geography and the strategy of multinational enterprises. Journal of International Business Studies, 35(2), 81-98.

Cantwell, J. (2009). Location and the multinational enterprise. Journal of International Business Studies, 40(10), 35-41.

Chen, S. (2004). Taiwanese IT firms' offshore R\&D in China and the connection with the global innovation network. Research Policy, 33, 337-349.

Chen, S. \& Wen, P. (2011) Industrial upgrading and global innovation networks: Taiwan case, paper to conference on The Economic Geography of ICT in Asia Pacific, University of Queensland, Brisbane, April 28-30.

Chen, S, Wen, P. \& Tai, C. (2011) China's 'good enough' innovation: Shanzhai handsets and Shanzhai economy, paper to conference on The Economic Geography of ICT in Asia Pacific, University of Queensland, Brisbane, April 28-30.

Cooke, P. (2012). Complex adaptive innovation systems. London: Routledge.

Cooke, P. (2013) Qualitative analysis and comparison of firm and system incumbents in the new ICT Global Innovation Network European Planning Studies, 21(6)1323-1340

Cooke, P., Boekholt, P., \& Tödtling, F. (2000). The governance of innovation in Europe. London: Frances Pinter.

Elola, A, Aranguren, M. \& Valdaliso, J. (2011) The competitive position of the Basque aerospatial cluster: A historical analysis, paper to conference on clusters in global value chains \& production networks: What is the role of innovation systems? San Sebastian, Deusto University/Orkestra, October 20-21.

Ernst, D. (2009). A new geography of knowledge in the electronics industry? Asia's role in global innovation networks, Policy Studies 54. Hawaii: East-West Center.

Geels, F. (2007). Analysing the breakthrough of rock ' $n$ ' roll (1930-1970): Multi-regime interaction and reconfiguration in the multi-level perspective. Technological Forecasting and Social Change, 74, 1411-1431.

Geertz, C. (1973). The interpretation of cultures. New York: Basic Books.

Gereffi, G., Humphrey, J., \& Sturgeon, T. (2005). The governance of global value chains. Review of International Political Economy, 12(1), 78-104.

Graham, J. (2010) App developers can dip into iFund's \$200 million pool, http://www.Usatoday.Com/tech/techinvestor/ 2010-09-16-ifund16_CV_N.Htm last downloading 20/9/2011.

Grove, A. (1996). Only the paranoid survive. New York: Doubleday.

Holland, J. (1998). Emergence. Helix: Reading MA.

Holland, J. (2006). Studying complex adaptive systems. Journal of Systems Science and Complexity, 19(1), 1-8.

Isaacson, W. (2011). Steve Jobs. London: Little Brown.

Juarrero, A. (2000). Dynamics in action: Intentional behavior as a complex system. Emergence, 2(2), 24-57.

Kauffman, S. (2008). Reinventing the sacred. New York: Basic Books.

Kingdom, J. (1984). Agendas. Longham, New York: Alternatives and Public Policies.

Lee, Y. (2011) Role of the S. Korean state in creating display industry clusters, paper to conference on the economic geography of ICT in Asia Pacific, University of Queensland, Brisbane, April 28-30.

Lewis, L. (2012). Villagers in despair as river runs black with residue of the digital revolution. The Times, March, 8, 32.

Lewis, M. (2010). The big short. New York: Harcourt Brace.

LMS (2011) App Genome Project Report, lookout mobile security, http://www.mylookout.com/appgenome, accessed 22. 2.2011.

Marschan-Peikkari, R., \& Welch, C. (2004). Handbook of qualitative research methods for international business. Cheltenham: Edward Elgar.

Martin, R. (2010). The Roepke lecture in economic geography - Rethinking regional path dependence: Beyond lock-in to evolution. Economic Geography, 86, 1-27.

Mitchell, M. (2009). Complexity: A guided tour. Oxford: Oxford University Press.

Mitleton-Kelly, E. (2011). Identifying the multi-dimensional problem space and co-creating an enabling environment. Emergence: Complexity \& Organization, 13, 3-25.

Mudambi, R. (2007). Offshoring: Economic geography and the multinational firm. Journal of International Business Studies, 38(1), 206

Mudambi, R. (2008). Location, control and innovation in knowledge-intensive industries. Journal of Economic Geography, $8(5), 699-725$.

Naughton, J. (2011). Business crash. The Observer, 11, 20,

Normann, R., \& Ramirez, R. (1993). From value chain to value constellation: Designing interactive strategy. Harvard Business Review, 71(4), 65-77.

Palmer, M., \& MacCarthy, C. (2011). Sony buys Ericsson share of handset venture. Financial Times, 28, 17.

Reinau, K. (2010). High-tech clusters and multinational corporations: Subsidiaries in political games, paper to conference on: Innovation and Institutional Embeddedness of Multinational Companies' February 26-27. Germany: University of Oldenburg.

Schmitz, H., \& Strambach, S. (2009). The organisational decomposition of innovation and global distribution of innovative activities: Insights and research agenda. International Journalof Technological Learning, Innovation \& Development, 2, 231-249.

Stoerring, D., \& Dalum, B. (2007). Cluster emergence: A comparative study of two cases in North Jutland, Denmark. In P. Cooke \& D. Schwartz (Eds.), Creative regions: Technology. Culture \& Knowledge Entrepreneurship, London: Routledge.

Sunley, P. (2011). Worlds of production: Conventions and the microfoundations of regional economies. In P. Cooke, B. Asheim, R. Boschma, R. Martin, D. Schwartz, \& F. Tödtling (Eds.), The Handbook of Regional Innovation \& Growth. Cheltenham: Edward Elgar.

Tichy, G. (2011). Innovation, product life cycle and diffusion: Vernon and beyond. In P. Cooke, B. Asheim, R. Boschma, R. Martin, D. Schwartz, \& F. Tödtling (Eds.), The Handbook of Regional Innovation \& Growth. Cheltenham: Edward Elgar. 
Tödtling, F., \& Trippl, M. (2005). One size fits all? Towards a differentiated regional innovation policy approach. Research Policy, 34, 1203-1219.

Trippl, M. (2011). Regional innovation systems and knowledge-sourcing activities in traditional industries-Evidence from the Vienna food sector. Environment and Planning A, 43, 1599-1616.

Vernon, R. (1966). International investment and international trade in the product cycle. Quarterly Journal of Economics, 2, 190-207.

Yeung, H. (2011) Industrial clusters, regional systems and global production networks: Strategic coupling through innovative learning, paper to conference on clusters in global value chains \& production networks: What is the role of innovation systems? San Sebastian, Deusto University/Orkestra, October 20-21.

Zaheer, S., \& Nachum, L. (2011). Sense of place: From location resources to MNE locational capital. Global Strategy Journal, 1, 96-108.

\section{Submit your manuscript to a SpringerOpen ${ }^{0}$ journal and benefit from:}

- Convenient online submission

- Rigorous peer review

Open access: articles freely available online

High visibility within the field

- Retaining the copyright to your article

Submit your next manuscript at $\boldsymbol{s p r i n g e r o p e n . c o m ~}$ 